\title{
Media Internalization and Conformity to Traditional Masculine Norms in Relation to Body Image Concerns Among Men
}

\author{
Arthur Y. De Jesus, Lina A. Ricciardelli \\ Deakin University \\ Ann Frisén \\ University of Gothenburg \\ Linda Smolak \\ Kenyon College \\ Zali Yager \\ La Trobe University \\ Matthew Fuller-Tyszkiewicz \\ Deakin University \\ Phillippa C. Diedrichs \\ University of West of England \\ Debra Franko \\ Northeastern University \\ Kristina Holmqvist Gattario \\ University of Gothenburg
}

Corresponding author:

Lina Ricciardelli

lina.ricciardelli@deakin.edu.au

61392446866

Cite as: De Jesus, A.Y., Ricciardelli, L.A., Frisen, A., Smolak, L., Yager, Z., Fuller-Tyszkiewicz, M., Diedrichs, P.C., Franko, D., Holmqvist Gattario, K. (2015). Media Internalization and Conformity to Traditional Masculine Norms in Relation to Body Image Concerns Among Men. Eating Behaviours, 18, 137-142. 


\begin{abstract}
Previous studies have separately examined conformity to masculine norms and internalization of body ideals in the media in relation to the drive for muscularity (DM). This study was designed to examine these factors together in relation to DM, and further examine how they may differ in relation to drive for thinness (DT) and drive for leanness (DL). Participants were 284 Australian males between ages 18 to 42 . They completed validated measures that assessed DM, DT, DL, male gender role norms, and internalization of body ideals. The findings showed that internalization of body ideals mediated the relationship between masculine role norms and body image in the case of both DM and DL. However, masculine norms and internalization were independent predictors of DT. Our findings contribute to further understanding of the roles that the media and masculine norms have in shaping men's drive for muscularity, leanness, and thinness. Longitudinal research is needed to confirm the nature and direction of these relationships.
\end{abstract}

Keywords: male, muscularity, leanness, thinness, masculine norms, media internalization 


\section{Introduction}

Traditionally, body image issues were considered problems that occurred primarily among women. This view has been challenged by increasing evidence which indicates that men also experience significant body image concerns, and the rising prevalence of men diagnosed with eating disorders and body dysmorphic disorders, such as anorexia nervosa and muscle dysmorphia (Pope et al., 2005; Strother, Lemberg, Standford, \& Turberville, 2012). While a significant number of men display problems at the clinical level, men in the general community also display subclinical levels of body image concerns that involve attitudes and behaviors associated with muscularity, leanness, and/or thinness (Bergeron \& Tylka, 2007; Fernandez \& Pritchard, 2012; Smolak \& Murnen, 2008). These subclinical levels of body image concerns may involve health risk behaviors, such as the use of anabolic steroids to build muscle (Olivardia, Pope, Borowiecki, \& Cohane, 2004) and frequent weight training (Tod, Hall, \& Edwards, 2012).

A motivation underlying body image concerns is the desire for a particular body shape, and the body shape that men regularly desire involves muscularity (Cafri et al., 2005; McCreary et al., 2005). This desire for a muscular body is referred to as 'Drive for Muscularity' (DM), and is described as a preoccupation with attaining large muscles concentrated on one's upper body (McCreary, Sasse, Saucier, \& Dorsch, 2004). Although men generally have a desire to be more muscular, there are also men who desire to be thinner (Kelley, Neufeld, \& Musher-Eizenman, 2010). This desire for a thin and slender body is referred to as 'Drive for Thinness' (DT) (Garner, 2002; Grossbard, Atkins, Geisner, \& Larimer, 2013). Additionally, Smolak and Murnen (2008) defined another component that has been termed 'Drive for Leanness' (DL), which is described as a desire for a lean body with well-defined muscles and low body fat. Unlike the DT, where the goal is to have almost no body fat, and the DM, where the goal is to have large muscles, the desire in DL is for a body shape that is specifically lean and similar to looking 'athletic' (Smolak \& Murnen, 2008).

The different body shapes desired by college-aged men were confirmed in Smolak and Murnen's (2008) study that distinguished DL from both DM and DT, with correlations among the three constructs ranging from .41 to .53 . Similarly, Tod and colleagues' (2012) study with college-aged men not only found the three constructs to be related, but also showed that frequent weight training and protein supplements consumption were associated more with higher DL than with either DM or DT. 
In order to better understand the nature of different body image concerns in men, researchers have begun to examine how they are shaped by sociocultural factors, such as male gender role norms (McCreary, Saucier, \& Courtenay, 2005) and the internalization of body ideals in the media (Diedrichs, 2012). Male gender role norms are important because they reflect and reinforce social and cultural expectations for men to conform to particular behaviors and attitudes (Levant, 2011; Thompson \& Pleck, 1986). In addition, these gender role norms are viewed as being reinforced by powerful social agents, such as the media, which are then adopted or internalized by men (Thompson, Schaefer, \& Menzel, 2012; Tiggemann, 2012). However, so far previous studies have either examined male gender role norms or media internalization, but not both factors together.

Studies have shown that men's desire to be more muscular is closely associated with male gender role norms, particularly involving masculinity (Hunt, Gonsalkorale, \& Murray, 2013; Mahalik et al., 2003; McCreary, Saucier, \& Courtenay, 2005). To assess men’s conformity to masculine gender roles, Mahalik and colleagues (2003) developed specific conformity to masculine norms (CMN) subscales, and found that the Winning norm subscale, which assesses the drive to win (e.g., In general, I will do anything to win") was uniquely associated with DM. The importance of Winning highlights social pressures for men to succeed in all aspects of their lives (e.g. school, workplace, sports) (Levant, 2011; Parent \& Moradi, 2009). Smolak and Murnen (2008) also found that the Disdain for Homosexual norm, which assesses the aversion to the prospect of being gay, or being thought of as gay" (e.g., "I would be furious if someone thought I was gay"), along with the Winning norm, to be associated with DM in college-aged men. The Disdain for Homosexuals norm is important to DM, as men are traditionally socialized to associate feminine and homosexual behaviors with weakness, and to present their selves as strictly heterosexual (Levant, 2011; Parent \& Moradi, 2009; Thompson \& Pleck, 1986).

The relationship between internalization of the media and DM has also been demonstrated. Several studies with college-aged men have shown that media internalization is associated with DM (Daniel \& Bridges, 2010; Frederick et al., 2007; Giles \& Close, 2008; Karazsia \& Crowther, 2009). In addition, Cramblitt and Pritchard's (2013) study showed that media internalization mediated the relationship between hours of television exposure and DM in college-aged men

Other studies have also examined the relationship between male gender role norms or the internalization of body ideals in relation to men's DT and DL. For example, Smolak and Murnen (2008) found that higher Pursuit of Status, which assesses being pleased with being 
thought of as important" (e.g., "It feels good to be important") was associated with lower DT, while conformity to Winning and Disdain for Homosexuals subscales were associated with higher DL (Smolak \& Murnen, 2008). It seems that men who placed greater importance on the pursuit of a high social status were less likely to want to be thin. In another study, Fernandez and Pritchard (2012) showed that media internalization was associated with higher DT in college-aged men. Similarly, Tod, Edwards, and Hall (2013) found that media internalization was associated with higher DL.

\subsection{Present study}

The reviewed studies have shown that male gender role norms and media internalization are related to men's body image concerns but none of the previous studies have examined the two factors together. This is the first study to examine the relationship between male gender role norms and media internalization, and also examine how both factors work together in predicting body image concerns. Given the media's role in reinforcing the social standards derived from gender role norms, it was expected that male gender role norms would be associated with media internalization. In addition, it was expected that the relationship between male gender role norms and body image concerns would be mediated by media internalization. The relationships were examined separately for DM, DT, and DL, given that different male gender role norms have been found to be associated with each body image domain. Differences attributable to men's body mass index (BMI) were controlled, as some studies have shown that men's body image concerns are related to their BMI (e.g., Daniel \& Bridges, 2010).

\section{Material and methods}

\subsection{Participants}

Participants were 284 male volunteers living in Australia, aged between 18 to 42 years $(M=22.63, S D=3.53)$. Six participants $(2 \%)$ did not provide their age. The majority of participants identified as White or European (69\%), followed by Asian (9.5\%), more than one ethnicity (3.9\%), South Asian (3.2\%), and as other (1.5\%). The majority of participants were studying full-time (61.2\%), while the others were working full-time (31.4\%), unemployed $(2.3 \%)$, on leave $(1.2 \%)$, or did not specify $(3.9 \%)$.

\subsection{Measures}

\subsubsection{Conformity to masculine norms}

Conformity to masculine norms is measured by the Conformity to Masculine Norms Inventory-46 (CMNI-46; Parent \& Moradi, 2009). This short version consists of 46 items 
with 9 subscales. Each of the subscales has displayed high internal consistency with collegeaged men: Winning (.83), Emotional Control (.86), Risk-Taking (.84), Violence (.86), Playboy (.84), Self-Reliance (.84), Primacy of Work (.77), Power over Women (.78), and the renamed Heterosexual Self-Presentation (.91) (formerly Disdain for Homosexuals) (Parent \& Moradi, 2009). Participants answered items on a 4-point scale ranging from "Strongly Disagree" (0) to "Strongly Agree" (3). Higher scores indicate higher levels on each subscale.

\subsubsection{Media internalization}

The Internalization-General Subscale and the Internalization-Athlete Subscale of the Sociocultural Attitudes Towards Appearance Questionnaire-3 (SATAQ-3; Thompson, van den Bert, Roehrig, Guarda, \& Heinberg, 2004) were used to assess Media Internalization. They were designed to assess an individual's internalization of body ideals as viewed in various media (i.e. TV, movies, and magazines), which consist of a total 14 items (Thompson et al., 2004). Participants indicated their answer to items, such as "I compare my body to bodies of TV and movie stars" and "I compare my body to sports athletes in magazines", on a 5-point scale ranging from "Definitely Disagree" (1) to "Definitely Agree" (5). Higher scores indicate internalization of media ideals. The SATAQ-3 has demonstrated a high internal consistency with college aged men $(\alpha=$.94) (Karazsia \& Crowther, 2008).

\subsubsection{Drive for muscularity}

The Drive for Muscularity Scale (DMS; McCreary, Sasse, Saucier, \& Dorsch 2004) is a 15-item scale that assesses an individual's excessive concern with muscularity. Participants responded to items such as "I think I would feel stronger if I gained a little more muscle mass" on a 6-point scale ranging from "Always" (1) to "Never" (6), which was reversescored. Higher scores indicate higher DM. McCreary and colleagues (2004) reported high internal consistency with college-aged men $(\alpha=.93)$.

\subsubsection{Drive for thinness}

The Drive for Thinness Scale is a 7-item subscale within the Eating Disorder Inventory - 3 (EDI-3 DFT; Garner, Olmstead, \& Polivy, 1983; Spillane, Boerner, Anderson, $\&$ Smith, 2004) that assesses an individual's preoccupation with weight, dieting, or becoming thin. Participants answer items that include "I am terrified of gaining weight", and rate their answers on a 6-point scale that range from "Never (1) to "Always" (6). Higher scores on the scale indicate higher DT. EDI-DT yielded moderately high internal consistency with adult men $(\alpha=.77)$ (Spillane et al., 2004). 


\subsubsection{Drive for leanness}

Smolak and Murnen (2008) developed the 6-item Drive for Leanness Scale (DLS) to assess an individual's drive for leanness, which is distinguishable from the drive for muscularity and the drive for thinness. The items assess attitudes towards having a lean body (Smolak \& Murnen, 2008). Participants rate their answers to items, such as "My goal is to have well-toned muscles", on a 6-point scale that range from "Never" (1) to "Always" (6). Higher scores indicate higher DL. Smolak and Murnen (2008) also reported high internal consistency with college-aged men $(\alpha=.79)$.

\subsubsection{Body Mass Index (BMI)}

Participants self-reported their height and weight, which were converted and calculated $\left(\mathrm{kg} / \mathrm{m}^{2}\right)$ to obtain a BMI score. The average height reported was 179.56 $(S D=11.71)$ centimeters ( 5 feet, 8 inches) and the average weight was $78.29(S D=12.07)$ kilograms (172.60 pounds). According to National Institute of Health (2013) classifications for BMI, participants with scores below 18 were considered 'underweight' (5\%); scores between 18-24.9 considered 'normal weight' (60.5\%); scores between 25-30 considered 'overweight' (25\%); and a score above 30 considered 'obese' (9.5\%). The average BMI for the sample was $24.12(S D=3.81)$.

\subsection{Procedure}

Deakin University Ethics' approval was obtained to conduct the study.

Advertisements with details of the study were placed throughout the university's gym facilities, cafeterias, student lounge areas, classroom hallways, and via electronic advertising on the social networking website, Facebook. Hard copies of the survey were also given out around the university campus, using convenience and snowball sampling techniques.

Participants were required to be male and aged 18 or above. Participants who completed the survey were provided with the opportunity to win one of ten $\$ 30$ department store vouchers.

The first part of the survey included the Plain Language Statement describing the background and aims of the research. Informed consent and voluntary participation were inferred with the completion of the survey (National Health and Medical Research Council [NHMRC], 2007). The survey was completed online (70\%), or in hard copy. The response rate for the hard copies, which were returned via reply post to the second author, was $20 \%$. Out of 456 submitted online surveys, 199 (43.7\%) completed all of the measures for this study. The combined completed online (199) and hard copy (85) surveys totalled the 284 participants of this study. 


\subsection{Data-analytic strategy.}

SPSS was used to conduct bivariate correlations and multiple regression. A standard regression analysis was conducted to determine if $\mathrm{CMN}$ subscales predicted Internalization (model 1). This is also a requirement to demonstrate if Internalization mediates the relationship between the CMN subscales and body image concerns (Baron \& Kenny, 1986). Secondly, hierarchical multiple regression analyses were conducted to determine if BMI, conformity to Self-Reliance, Heterosexual Self-Presentation, Emotional Control, Winning, Primacy of Work, Power Over Women, Playboy, Risk Taking, and Violence subscales predicted DM, DT, and DL (model 2). Lastly, Internalization was entered in the second step of the regression model after the CMN subscales and BMI in predicting DM, DT, and DL (model 3). Sobel test was used to evaluate the significance of the mediating effects (Sobel, 1982).

\section{Results}

\subsection{Preliminary data analyses}

Values were found to be missing at random, with cases identified to be less than 5\% of the sample. The identified missing values were replaced using the expectation maximisation technique prior to running the main analyses (Tabachnick \& Fidell, 2007). The 284 cases were screened and found to meet the assumptions for multiple regressions.

Bivariate correlations, means, standard deviations, and Cronbach alpha coefficients of all variables are summarised in Table 1. DM, DT, and DL were all correlated with each other; the relationship between DM and DL $(.55, p<.01)$ was moderate while the relationship between DM and DT $(.27, p<.01)$ and between DT and DL $(.24, p<.01)$ were low.

Media Internalization correlated weakly with four of the CMN subscales: Winning $(.23, p<.01)$, Risk-Taking $(.14, p<.05)$, Heterosexual Self-Presentation $(.13, p<.05)$, and Playboy $(.13, p<.05)$. Media Internalization was also moderately correlated with each type of body image concern, DM (.54, $p<.01)$, DL $(.65, p<.05)$, and DT $(.41, p<.01)$.

Five of the CMN subscales were weakly correlated with DM: Winning $(.28, p<.01)$, Heterosexual Self-Presentation (.28, $p<.01)$, Power Over Women, $(.27, p<.01)$, Playboy (.17, $p<.01)$, and Risk Taking $(.15, p<.05)$. Six of the CMN subscales were weakly correlated with DL: Self-Reliance $(.15, p<.05)$, Heterosexual Self-Presentation $(.17, p<.01)$, Winning (.32, $p<.01)$, Power Over Women (.12, $p<.05)$, Playboy (.17, $p<.05)$, and Risk Taking $(.15, p<.05)$. Only one CMN subscale weakly correlated with DT: Primacy of Work $(.17, p<.01)$. 
Lastly, BMI and age, on the whole, were found to be unrelated to the main measures. Only BMI correlated weakly and negatively with Heterosexual Self-Presentation (-.12, $p<.05)$. Age correlated weakly and negatively with the subscales Heterosexual SelfPresentation, Winning, and Power Over Women (-.17, $p<.01)$, and with Internalization (.14, $p<.05)$ and DL $(.13, p<.05)$.

\subsection{Predictors of media internalization}

Model 1 in Table 2 displays the standardized coefficients from regression analyses of variables that predicted Internalization. Winning, Power Over Women, Playboy, and Heterosexual Self-Presentation were significant predictors of Internalization, which met the precondition, to examine this variable as a mediator, according to the Baron and Kenny (1986) method.

\subsection{Direct and indirect predictors of drive for muscularity}

As indicated in Table 2, Model 2 for DM shows there were two unique significant variables that predicted DM. These were Winning $(\beta=.18, p<.01)$ and Heterosexual SelfPresentation $(\beta=.18, p<.05)$ which equally predicted DM. However, as shown in Table 2 , for model 3, Winning and Heterosexual Self-Presentation became non-significant after the inclusion of Internalization. Internalization $(\beta=.50, p<.01)$ was found to mediate the relationship between Winning and $\mathrm{DM}(\beta=.07, n . s$. $)$. To further investigate this effect, a Sobel test was conducted, which indicated full mediation $\left(\mathrm{z}^{\prime}=3.22, p<.01\right)$. Internalization was also found to mediate the relationship between Heterosexual Self-Presentation and DM $(\beta=.10, n . s$.$) , and full mediation was indicated after conducting a Sobel test ( \mathrm{z}^{\prime}=2.20, p<$ .05). On the other hand, after the inclusion of Internalization, Power Over Women became significant, $(\beta=.17, p<.01)$, thus indicative of a suppressor effect (Cohen, Coehn, West, \& Aiken, 2003).

\subsection{Direct and indirect predictors of drive for leanness}

As summarized in Table 2, Model 2 showed that four variables significantly predicted DL: Winning $(\beta=.28, p<.01)$, Heterosexual Self-Presentation $(\beta=.15, p<.05)$, Playboy $(\beta=.15, p<.05)$, and BMI $(\beta=.11, p<.05)$. As indicated in Model 3, Internalization $(\beta=.59$, $p<.01$ ) was shown to mediate the relationship between Heterosexual Self-Presentation and $\operatorname{DL}(\beta=.05, n . s$.$) . The Sobel test demonstrated full mediation \left(\mathrm{z}^{\prime}=2.22, p<.05\right)$.

Internalization was also shown to mediate the relationship between Playboy and DL $(\beta=.07$, n.s.), and the Sobel test indicated full mediation $\left(\mathrm{z}^{\prime}=2.02, p<.05\right)$. Lastly, Internalization was found to be a partial mediator, as Winning $(\beta=.15, p<.01)$ was found to be a weaker but 
remained a significant predictor of DL, and this was confirmed by the Sobel test $\left(\mathrm{z}^{\prime}=3.27, p\right.$ $<.01)$.

\subsection{Direct and indirect predictors of drive for thinness}

Model 2 showed that DT was significantly predicted by only one variable, Primacy of Work $(\beta=.15, p<.05)$ (see Table 2$)$. Primacy of Work did not predict Internalization, and thus mediation could not be assessed. However, Internalization in model 3, was a significant and independent predictor of DT $(\beta=.42, p<.01)$.

\section{Discussion}

The findings supported the relationship between masculine norms and media internalization, which is consistent with the view that the media represents and reinforces gender role norms (Thompson, et al., 2012; Tiggemann, 2012). Four of the CMN subscales were found to be related to media internalization: Winning, Heterosexual Self-Presentation, Playboy, and Power Over Women. These norms reflect the content of many television shows where there is an overemphasis on competition and winning, an underrepresentation of gay men, pursuit of casual sex, and much focus on the objectification of women (Collins, 2011; Dallesasse \& Kluck, 2013). In addition, our study showed that conformity to masculine norms and internalization of the media differentially predicted DM, DT, and DL; and media internalization was found to mediate male gender role norms in the case of DM and DL.

\subsection{Drive for muscularity}

Media internalization was found to mediate the relationship between two of the CMN subscales and DM. These were conformity to Winning and Heterosexual Self-Presentation, which have been previously shown to be directly associated with higher DM (e.g., Smolak \& Murnen, 2008). However, our findings suggest that these norms are reinforced in the media with idealized messages that men have internalized, and it is via internalization that they contribute to higher DM.

One norm that also predicted DM but that was not mediated by media internalization was Power Over Women. Power Over Women assesses men's general perceived control over women (Parent \& Moradi, 2010) and appears to be an important reason why men strive to achieve muscularity. Swami et al. (2013) also found that aggressive behavior and dominant attitudes towards women was associated with higher DM. Moreover, experimental studies has shown that if this aspect of masculinity is threatened then men aspire for greater muscularity (Hunt, Gonsalkorale, \& Murray, 2013; Mills \& D’alfonso, 2007). 


\subsection{Drive for leanness}

Media internalization was also found to mediate the relationship between three of the CMN subscales and DL. These were conformity to Winning, Heterosexual Self-Presentation, and Playboy. Winning and Heterosexual Self-Presentation have also been shown to be directly associated with higher DL and as in a previous study, these did not differentiate DL from DM (Smolak \& Murnen, 2008). In this study, the masculine norm Playboy, which endorses sexual activities with casual partners (Parent \& Moradi, 2010) was only related to DL. This aspect of body image may be perceived to be more physically attractive and advantageous when competing for short-term relationships (Lanzieri \& Cook, 2013; Li et al., 2013).

However, as with DM, our findings suggest that masculine norms are represented in the media with idealized messages, and it is again through internalization that these messages contribute to higher DL. The Winning norm was the only subscale to remain significantly related to DL, as shown by the partial mediation of media internalization. As winning assesses men's general competitiveness (Parent \& Moradi, 2010), this finding suggests that the DL is particularly shaped by expectations that encourage men to behave competitively.

\subsection{Drive for thinness}

The relationship between Primacy of Work and DT was not mediated by media internalization. The media usually does not display qualities associated with prioritizing work, such as commitment and perseverance, but instead advocates for 'quick-fix' solutions to weight loss (Furnham \& Paltzer, 2010; McKay, et al., 2005). The media highlights how obesity is often stigmatized, and this cultivates a fear of gaining weight and the idealization of thinness (Ambwani, et al., 2014). Moreover, given the traditional male role as 'provider' and the importance of career achievements that are often highly regarded for men (Levant, 2011), our findings suggest that this is an alternative motivation underlying men's DT. As reflected by Primacy of Work, men's sense of success and discipline are required in order to achieve one's desired levels of thinness.

\subsection{Limitations and conclusions}

Limitations of the study need to be noted. Given that this was a cross-sectional study, it is not possible to draw causal inferences. A longitudinal approach is needed to examine the directional nature of the relationships (e.g., Mellor, Fuller-Tyszkiewicz, McCabe, \& Ricciardelli, 2010), and how these may differ at various stages of development (Ricciardelli, McCabe, Lillis, \& Thomas, 2006). Additionally, the majority of men identified as White/European, which limits the generalizability of the findings to other ethnic and cultural 
backgrounds. The response rate from the hardcopy survey was also low and only $43.7 \%$ of men who began the online survey completed it. Some of the men provided feedback that the survey was too long but males have generally been found to be less likely to participate in research than females (Galea \& Tracy, 2007).

In addition, to gender role norms and media internalization, other factors have also been found to be related to men's body image concerns. These include sexual orientation (Marino Carper et al., 2010); relationship status (Giles \& Close, 2008); athletic involvement (Steinfeldt et al., 2011); peer pressure an social comparisons (Karazsia \& Crowther, 2009); self-objectification (Daniel \& Bridges, 2010; Smolak \& Murnen, 2008); and depressive symptoms (Grossbard, Atkins, Geisner \& Larimer, 2013). In order to more fully understand the development of men's body image concerns, further research is now needed to examine the relative influence of these factors and how they may also mediate and/or moderate the relationships demonstrated in this study.

Overall, the current findings contribute to understanding the differences that distinguish the three types of body image concerns among men, and they highlight the importance of examining both conformity to masculine norms and the internalization of media ideals. In the case of DM and DL, we found that the internalization of idealized appearance-related messages from the media mediated conformity to masculine norms. In the case of DT, we found that internalization of the media and masculine norms were independent influences. Future studies need to continue to examine each of the three types of body image concerns so that we develop a more comprehensive understanding of the multifaceted nature of men's body image.

\section{References}

Ambwani, S., Thomas, K. M., Hopwood, C. J., Moss, S. A., \& Grilo, C. M. (2014). Obesity stigmatization as the status quo: Structural considerations and prevalance among young adults in the U.S. Eating Behaviors, 15, 366-370. DOI: 10.1016/jeatbeh.2014.04.005

Baron, R. M., \& Kenny, D. A. (1986). The moderator-mediator variable distinction in social psychological research: Conceptual, strategic, and statistical considerations. Journal of Personality and Social Psychology, 51, 1173-1182.

Bergeron, D., \& Tylka, T. L. (2007). Support for the uniqueness of body dissatisfaction from drive for muscularity among men. Body Image, 4, 288-295. DOI: 10.1016/j.bodyim.2007.05.002 
Cafri, G., Thompson, J. K., Ricciardelli, L., McCabe, M., Smolak, L., \& Yesalis, C. (2005). Pursuit of the muscular ideal: Physical and psychological consequences and putative risk factors. Clinical Psychology Review, 25, 215-239. DOI: 10.1016.j.cpr.2004.09.003

Cohen, J., Cohen, P., West, S. G., \& Aiken, L. S. (2003). Applied multiple regression/correlation analysis for the behavioral sciences ( $3^{\text {rd }}$ ed.). Mahway, New Jersey: Lawrence Erlbaum Associates.

Collins, R. (2011). Content analysis of gender roles in media: Where are we now and where should we go? Sex Roles, 64, 290-298. DOI: 10.1007/s11199-010-9929-5

Cramblitt, B. \& Pritchard, M. (2013). Media's influence on the drive for muscularity in undergraduates. Eating Behaviors, 14, 441-446. DOI: 10.1016/j.eatbeh.2013.08.003

Dallesasse, S. L., \& Kluck, A. S. (2013). Reality television and the muscular ideal. Body Image, 10, 309-315. DOI: 10.1016/j.bodyim.2013.02.004

Daniel, S. \& Bridges, S. K. (2010). The drive for muscularity in men: Media influences and objectification theory. Body Image, 7, 32-38. DOI: 10.1016/j.bodyim.2009.08.003

Diedrichs, P. C. (2012). Media influences on male body image. In T. F. Cash (Ed.), Encyclopedia of body image and human appearance (Vol.2, pp. 547-553). London, UK and San Diego, CA: Academic Press.

Fernandez, S. \& Pritchard, M. (2012). Relationships between self-esteem, media influence, and drive for thinness. Eating Behaviors, 13, 321-325. DOI:

10.1016/j.eatbeh.2012.05.004

Frederick, D. A., Buchannan, G. M., Sadehgi-Azar, L., Haselton, M. G., Paplau, L. A., Lipinski, R. E., et al. (2007). Desiring the muscular ideal: Men's body dissatisfaction in the United States, Ukraine, and Ghana. Psychology of Men \& Masculinity, 8, 103-107. DOI: $10.1037 / 1524-9220.8 .2 .103$

Furnham, A. \& Paltzer, S. (2010). The portrayal of men and women in television advertisements: An updated review of 30 studies published since 2000. Scandinavian Journal of Psychology, 51, 216-236. DOI: 10.1111/j.1467-9450.2009.00772.x

Garner, D. M. (2002). Body image and anorexia nervosa. In T. F. Cash \& T. Pruzinsky (Eds.), Body image: A handbook of theory, research, and clinical practice (pp. 295303). New York: Guilford.

Garner, D. M., Olmstead, M. P. and Polivy, J. (1983). Development and validation of a multidimensional eating disorder inventory for anorexia nervosa and bulimia. International Journal of Eating Disorders, 2, 15-34. DOI: 10.1002/1098108X(198321)2:2<15::AID-EAT2260020203>3.0.CO;2-6 
Galea, S., \& Tracy, M. (2007). Participation rates in epidemiologic studies. Annals of Epidemiology, 17, 643-653. DOI: 10.1016/j.annepidem.2007.03.013.

Giles, D. C., \& Close, J. (2008). Exposure to 'lad magazines' and drive for muscularity in dating and non-dating young men. Personality and Individual Differences, 44, 1610 1616. DOI: 10.1016/j.paid.2008.01.023

Grossbard, J. R., Atkins, D. C., Geisner, I. M., \& Larimer, M. E. (2013). Does depressed mood moderate the influence of drive for thinness and muscularity on eating disorder symptoms among college men? Psychology of Men \& Masculinity, 14, 281-287. DOI: $10.1037 / \mathrm{a} 0028913$

Hunt, C. J., Gonsalkorale, K., \& Murray, S. B. (2013). Threatened masculinity and muscularity: An experimental examination of multiple aspects of muscularity in men. Body Image, 10, 290-299. DOI: 10.1016/j.bodyim.2013.02.007

Karazsia, B. T. \& Crowther, J. H. (2009). Social body comparison and internalization: Mediators of social influences on men's muscularity-oriented body dissatisfaction. Body Image, 6, 105-112. DOI: 10.1016/j.bodyim.2008.12.003

Karazsia, B. T., \& Crowther, J. H. (2008). Psychological and behavioral correlates of the SATAQ-3 with males. Body Image, 5, 109-115. DOI: 10.1016/j.bodyim.2007.08.004

Kelley, C. C., Neufeld, J. M., Musher-Eizenman, D. R. (2010). Drive for thinness and drive for muscularity: Opposite ends of the continuum or separate constructs? Body Image, 7 , 74-77. DOI: $10.1016 /$ j.bodyim .2009.09.008

Lanzieri, N. \& Cook, B. J. (2013). Examination of muscularity and body fat depictions in magazines that target heterosexual and gay men. Body Image, 10, 251-254. DOI: 10.1016/j.bodyim.2012.12.003

Levant, R. F. (2011). Research in the psychology of men and masculinity using the gender role strain paradigm as a framework. American Psychologist, 66, 765-776. DOI: $10.1037 / \mathrm{a} 0025034$

Li, N. P., Yong, J. C., Tov, W., Sng, O., Fletcher, G., Valentine, K. A., Jiang, Y. F., \& Balliet, D. (2013). Mate preferences do predict attraction and choices in the early stages of mate selection. Journal of Personality and Social Psychology, 105, 757-776. DOI: $10.1037 / \mathrm{a} 0033777$

Mahalik, J. R., Locke, B. D., Ludlow, L. H., Diemer, M. A., Scott, R. J., Gottfried, M., \& Freitas, G. (2003). Development of the Conformity to Masculine Norms Inventory. Psychology of Men \& Masculinity, 4, 3-25. DOI:10.1037/1524-9220.4.1.3 
Marino Carper, T. L., Negy, C., \& Tantleff-Dunn, S. (2010). Relations among media influence, body image, eating concerns, and sexual orientation in men: A preliminary investigation. Body Image, 7, 301-309. DOI: 10.1016/j.bodyim.2010.07.002

McCreary, D. R., Saucier, D. M., \& Courtenay, W. H. (2005). The drive for muscularity and masculinity: Testing the associations among gender-role traits, behaviors, attitudes, and conflict. Psychology of Men \& Masculinity, 6, 83-94. DOI: 10.1037/1524-9220.6.2.83

McCreary, D. R., Sasse, D. K., Saucier, D. M., \& Dorsch, K. D. (2004). Measuring the Drive for Muscularity: Factorial validity of the Drive for Muscularity Scale in men and women. Psychology of Men \& Masculinity, 5, 49-58. DOI: 10.1037/1524-9220.5.1.4

McKay, J., Mikosza, J., \& Hutchins, B. (2005). 'Gentlemen, the lunchbox has landed': Representations of masculinities and men's bodies in the popular media. In M. S. Kimmel, J. Hearn, \& R. W. Connell (Eds.), Handbook of studies on men and masculinities (pp. 270-288). Thousand Oaks, CA: Sage.

Mellor, D., Fuller-Tyszkiewicz, M., McCabe, M. P., \& Ricciardelli, L. A. (2010). Body image and self-esteem across age and gender: A short-term longitudinal study. Sex Roles, 63, 672-681. DOI: 10.1007/s11199-010-9813-3

Mills, J. S. \& D'alfonso, S. R. (2007). Competition and male body image: Increased drive for muscularity following failure to a female. Journal of Social and Clinical Psychology, 26, 505-518. DOI: 10.1521/jscp.2007.26.4.505

National Health and Medical Research Council (2007). National Statement on Ethical Conduct in Human Research 2007-Updated May 2013. Canberra: Australian Government Publishing Service.

National Institute of Health (2013). Body Mass Index calculation and chart. Retrieved from: http://www.nhlbi.nih.gov/guidelines/obesity/BMI/bmi-m.htm

Olivardia, R., Pope, Jr., H. G., Borowiecki III, J. J., \& Cohane, G. H. (2004). Biceps and body image: The relationship between muscularity and self-esteem, depression, and eating disorder symptoms. Psychology of Men \& Masculinity, 5, 112-120. DOI: $10.1037 / 1524-9220.5 \cdot 2.112$

Parent, M. C., \& Moradi, B. (2009). Confirmatory factor analysis of the Conformity to Masculine Norms Inventory and development of the Conformity to Masculine Norms Inventory-46. Psychology of Men \& Masculinity, 10, 175-189. DOI: 10.1037/a0015481

Pope, C. G., Pope, H. G., William, M., Fay, C., Olivardia, R., \& Phillips, K. A. (2005). Clinical features of muscle dysmorphia among males with body dysmorphic disorder. Body Image, 2, 395-400. DOI: 10.1016/j.bodyim.2005.09.001 
Ricciardelli, L. A., McCabe, M. P., Williams, R. J., Thompson, J. K. (2007). The role of ethnicity and culture in body image and disordered eating among males. Clinical Psychology Review, 27, 582-606. DOI: 10.1016.j.cpr.2007.01.016

Ricciardelli, L. A., McCabe, M. P., Lillis, J., \& Thomas, K. (2006). A longitudinal investigation of the development of weight and muscle concerns among preadolescent boys. Journal of Youth Adolescence, 177-187. DOI: 10.1007/s10964-005-9004-7

Smolak, L., \& Murnen, S. K. (2008). Drive for leanness: Assessment and relationship to gender, gender role and objectification. Body Image, 5, 251-260. DOI: 10.1016/j.bodyim.2008.03.004

Sobel, M. E. (1982). 'Asymptotic confidence intervals for indirect effects in structural equation models' in Leinhardt, S. (ed.). Sociological Methodology, San Francisco: Jossey-Bass.

Spillane, N. S., Boerner, L. M., Anderson, K. G., \& Smith, G. T. (2004). Comparability of the Eating Disorder Inventory-2 between women and men. Assessment, 11, 85-93. DOI: $10.1177 / 1073191103260623$

Steinfeldt, J. A., Gilchrist, G. A., Steinfeldt, M. C., Halterman, A. W., \& Gomory, A. (2011). Drive for muscularity and conformity to masculine norms among college football players. Psychology of Men \& Masculinity, 12, 324-338. DOI: 10.1037/a0024839

Strother, E., Lemberg, R., Stanford, S., \& Turberville, D. (2012). Eating disorders in men: Under diagnosed, undertreated, and misunderstood. Eating Disorders, 20, 346-355. DOI: $10.1080 / 10640266.2012 .715512$

Swami, V., Neofytou, R. V., Jablonska, J., Thirlwell, H., Taylor, D., \& McCreary, D. R. (2013). Social dominance orientation predicts drive for muscularity among British men. Body Image, 10, 653-656. DOI: 10.1016/j.bodyim.2013.07.007

Tabachnick, B. G. \& Fidell, S. L. (2007). Using multivariate statistics (5th ed.). Sydney: Pearson Education.

Thompson, J. K., Schaefer, L. M., \& Menzel, J. E. (2012). Internalization of thin-ideal and muscular-ideal. In T. F. Cash (Ed.), Encyclopedia of body image and human appearance (Vol.2, pp. 499-504). London, UK and San Diego, CA: Academic Press.

Thompson, J. K., van den Bert, P., Roehrig, M., Guarda, M. S., \& Heinberg, L. J. (2004). The Sociocultural Attitudes Towards Appearance Scale-3 (SATAQ-3): Development and validation. International Journal of Eating Disorders, 35, 293-304. DOI: 10.1002/eat. 10257 
Thompson, J. K., \& Pleck, J. H. (1986). The structure of male role norms. American Behavior Scientist, 29, 531-543. DOI: 10.1177/000276486029005003

Tiggemann, M. (2012). Sociocultural perspectives on body image. In T. F. Cash (Ed.), Encyclopedia of body image and human appearance (Vol.2, pp. 758-765). London, UK and San Diego, CA: Academic Press.

Tod, D., Edwards, C., \& Hall, G. (2013). Drive for leanness and health-related behavior within a social/cultural perspective. Body Image, 10, 640-643. DOI: 10.1016/j.bodyim.2013.05.002

Tod, D., Hall, G., Edwards, C. (2012). Gender invariance and correlates of the Drive for Leanness Scale. Body Image, 9, 555-558. DOI: 10.1016/j.bodyim.2012.06.004 


\section{Table 1}

Correlations, means (standard deviations), and Cronbach alpha coefficients among masculine norms, internalization, BMI, and age

\begin{tabular}{|c|c|c|c|c|c|c|c|c|c|c|c|c|}
\hline Intercorrelations & 1 & 2 & 3 & 4 & 5 & 6 & 7 & 8 & 9 & 10 & 11 & 12 \\
\hline 1. Emotional Control & - & & & & & & & & & & & \\
\hline 2. Self-Reliance & $.54^{* *}$ & - & & & & & & & & & & \\
\hline $\begin{array}{l}\text { 3. Heterosexual } \\
\text { Self-Presentation }\end{array}$ & $.26^{* *}$ & $.23 * *$ & - & & & & & & & & & \\
\hline 4. Winning & .10 & $.20^{* *}$ & $.28 * *$ & - & & & & & & & & \\
\hline 5. Primacy of Work & .10 & $.19^{* *}$ & .07 & $.17^{* *}$ & - & & & & & & & \\
\hline 6. Power Over Women & $.14^{*}$ & $.23^{* *}$ & $.52 * *$ & $.38^{* *}$ & $.22 * *$ & - & & & & & & \\
\hline 7. Violence & $.12 *$ & .04 & $.19 * *$ & $.16^{* *}$ & -.00 & $.27 * *$ & - & & & & & \\
\hline 8. Playboy & $.13^{*}$ & $.13^{*}$ & .10 & $.20^{* *}$ & $.15^{*}$ & $.33 * *$ & $.26^{* *}$ & - & & & & \\
\hline 9. Risk Taking & -.05 & .00 & $.13^{*}$ & $.22 * *$ & -.05 & $.17^{*}$ & $.19 * *$ & $.23 * *$ & - & & & \\
\hline 10. Drive for Muscularity & .06 & .09 & $.28 * *$ & $.28^{* *}$ & .04 & $.27 * *$ & .09 & $.17 * *$ & $.15^{*}$ & - & & \\
\hline 11. Drive for Leanness & .02 & $.15^{*}$ & $.17 * *$ & $.32 * *$ & .00 & $.12 *$ & .00 & $.17^{*}$ & $.15^{*}$ & $.55^{* *}$ & - & \\
\hline 12. Drive for Thinness & -.08 & .01 & -.03 & .09 & $.17 * *$ & .06 & -.06 & .11 & -.03 & $.27 * *$ & $.24 * *$ & \\
\hline
\end{tabular}




\section{Table 1 (continued)}

\begin{tabular}{|c|c|c|c|c|c|c|c|c|c|c|c|c|c|c|c|}
\hline 13. Internalization & -.03 & .04 & $.13^{*}$ & $.23^{* *}$ & .03 & .04 & -.02 & $.13^{*}$ & $.14^{*}$ & $.54^{* *}$ & $.65^{*}$ & $.41^{* *}$ & - & & \\
\hline 14. BMI & .06 & .07 & $-.12 *$ & .05 & .03 & -.05 & -.02 & -.02 & -.05 & .02 & .11 & .08 & .05 & _ & \\
\hline 15. Age & -.10 & -.04 & $-.17 * *$ & $-.17 * *$ & -.10 & $-.17 * *$ & -.11 & .02 & -.08 & -.08 & $.13 *$ & .06 & $.14 *$ & .07 & - \\
\hline $\begin{array}{l}\text { Means } \\
\text { (Standard Deviations) }\end{array}$ & $\begin{array}{l}13.96 \\
(3.51)\end{array}$ & $\begin{array}{l}11.31 \\
(2.80)\end{array}$ & $\begin{array}{l}13.28 \\
(4.24)\end{array}$ & $\begin{array}{l}15.31 \\
(3.25)\end{array}$ & $\begin{array}{l}8.63 \\
(2.35)\end{array}$ & $\begin{array}{l}7.29 \\
(2.24)\end{array}$ & $\begin{array}{l}14.59 \\
(3.74)\end{array}$ & $\begin{array}{l}9.26 \\
(2.60)\end{array}$ & $\begin{array}{l}12.25 \\
(2.31)\end{array}$ & $\begin{array}{l}44.32 \\
(15.09)\end{array}$ & $\begin{array}{l}24.02 \\
(5.91)\end{array}$ & $\begin{array}{l}4.39 \\
(0.74)\end{array}$ & $\begin{array}{l}44.80 \\
(11.97)\end{array}$ & $\begin{array}{l}24.12 \\
(3.21)\end{array}$ & $\begin{array}{l}22.63 \\
(3.52)\end{array}$ \\
\hline Cronbach alpha & .91 & .85 & .90 & .88 & .76 & .87 & .84 & .88 & .82 & .91 & .88 & .77 & .94 & $\mathrm{~N} / \mathrm{A}$ & $\mathrm{N} / \mathrm{A}$ \\
\hline
\end{tabular}

Note. ${ }^{*} p<.05 * * p<.01$ 


\section{Table 2}

Standardized Coefficients from Hierarchical Regression Analyses of Variables Predicting Body Image Concerns $(N=284)$

\begin{tabular}{|c|c|c|c|c|c|c|c|}
\hline \multirow[b]{2}{*}{ Variable } & \multirow{2}{*}{ 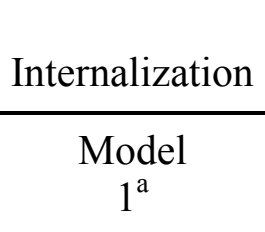 } & \multicolumn{2}{|c|}{$\begin{array}{l}\text { Drive for } \\
\text { Muscularity }\end{array}$} & \multicolumn{2}{|c|}{$\begin{array}{l}\text { Drive for } \\
\text { Leanness }\end{array}$} & \multicolumn{2}{|c|}{$\begin{array}{l}\text { Drive for } \\
\text { Thinness }\end{array}$} \\
\hline & & $\begin{array}{c}\text { Model } \\
2\end{array}$ & $\begin{array}{l}\text { Model } \\
3^{\mathrm{b}}\end{array}$ & $\begin{array}{c}\text { Model } \\
2\end{array}$ & $\begin{array}{l}\text { Model } \\
3^{b}\end{array}$ & $\begin{array}{c}\text { Model } \\
2\end{array}$ & $\begin{array}{c}\text { Model } \\
3^{\mathrm{b}}\end{array}$ \\
\hline $\begin{array}{l}\text { Emotional } \\
\text { Control }\end{array}$ & -.10 & -.03 & .02 & -.10 & -.04 & -.12 & -.07 \\
\hline Self-Reliance & .04 & .01 & -.01 & .12 & .10 & .02 & .00 \\
\hline $\begin{array}{l}\text { Heterosexual } \\
\text { Self-Presentation }\end{array}$ & $.16^{*}$ & $.18^{*}$ & .10 & $.15^{*}$ & .05 & .02 & -.10 \\
\hline Winning & $.22 * *$ & $.18^{* *}$ & .07 & $.28 * *$ & $.15 * *$ & .08 & -.01 \\
\hline Primacy of Work & .00 & .09 & -.03 & -.07 & -.07 & $.15^{*}$ & $.15^{* *}$ \\
\hline $\begin{array}{l}\text { Power Over } \\
\text { Women }\end{array}$ & $-.15^{*}$ & .09 & $.17 * *$ & -.09 & -.01 & .02 & .00 \\
\hline Violence & -.08 & -.03 & .01 & -.08 & -.04 & -.07 & -.04 \\
\hline Playboy & $.13^{*}$ & .09 & .03 & $.15^{*}$ & .07 & .11 & .06 \\
\hline Risk Taking & .08 & .05 & .01 & .06 & .02 & -.06 & -.09 \\
\hline BMI & .07 & .05 & .02 & $.11^{*}$ & .08 & .07 & .05 \\
\hline Internalization & & & $.50^{* *}$ & & $.59 * *$ & & $.42 * *$ \\
\hline
\end{tabular}

Note. ${ }^{\mathrm{a}}$ To meet preconditions to test for mediation (Baron \& Kenny, 1986), the main variables CMN subscales and BMI were entered in Model 1 to predict Internalization (the mediator).

${ }^{\mathrm{b}}$ In Model 3, Internalization was entered in the second step of the hierarchical regression.

$* p<.05 * * p<.01$ 